Cahiers $d u$ MONDE RUSSE

\section{Cahiers du monde russe}

Russie - Empire russe - Union soviétique et États indépendants

\title{
Jessica Allina-Pisano, The Post-Soviet Potemkin Village
}

\section{Alessandro Stanziani}

\section{OpenEdition}

\section{Journals}

Édition électronique

URL : https://journals.openedition.org/monderusse/6983

DOI : 10.4000/monderusse. 6983

ISSN : $1777-5388$

Éditeur

Éditions de l'EHESS

\section{Édition imprimée}

Date de publication : 28 décembre 2008

Pagination : 803-805

ISBN : 978-2-7132-2197-2

ISSN : $1252-6576$

Référence électronique

Alessandro Stanziani, "Jessica Allina-Pisano, The Post-Soviet Potemkin Village », Cahiers du monde russe [En ligne], 49/4 | 2008, mis en ligne le 24 décembre 2009, consulté le 03 septembre 2022. URL http://journals.openedition.org/monderusse/6983; DOI : https://doi.org/10.4000/monderusse.6983

Ce document a été généré automatiquement le 3 septembre 2022

Tous droits réservés 


\title{
Jessica Allina-Pisano, The Post- Soviet Potemkin Village
}

\author{
Alessandro Stanziani
}

\section{RÉFÉRENCE}

Jessica allina-PISANo, The Post-Soviet Potemkin Village. Politics and Property Rights

in the Black Earth. Cambridge : Cambridge University Press, 2008, $215+$ XXIII p.

1 Cet ouvrage est hors du commun à maints égards. Son objet d'étude (la privatisation des terres dans la Russie et l'Ukraine post-soviétiques), fort intéressant en soi, est traité avec une grande rigueur scientifique et apporte des résultats novateurs. L'usage de sources multiples (archives, enquêtes orales, bibliographie) est détaillé et justifié, tout comme le recours à des disciplines différentes (histoire, ethnographie, sociologie, droit, économie). Le tout est servi par une plume et un style, eux aussi, exceptionnels. S'agissant d'un premier livre, tiré de la thèse de l'auteur, on ne peut que se réjouir du succès de cette entreprise qui a duré huit ans.

2 L'ouvrage s'ouvre par une longue préface méthodologique sur les sources (orales, enquêtes, archives) et leur emploi. Bagage fondamental tant des historiens que des sociologues et des ethnographes, ce genre de considérations, trop souvent relégué en note ou juste énoncé tel quel, est ici non seulement détaillé, mais justifié en le confrontant à d'autres méthodes.

Dans une même démarche, l'introduction évoque de manière élégante et convaincante les thèses de l'auteur, puis envisage les hypothèses et arguments alternatifs, sans tomber dans l'attitude si répandue qui consiste à présenter ces derniers de manière caricaturale afin de mieux justifier sa propre méthode.

4 Pourquoi la privatisation des terres collectives, malgré les incitations de ses promoteurs et des institutions internationales, n'a-t-elle jamais été réellement mise en pratique, creusant ainsi un fossé important entre le droit théorique et sa mise en pratique ? Telle est la question centrale de l'ouvrage. La réponse est que ceci est dû à la fois aux 
résistances des responsables locaux (élites politiques et directeurs des fermes collectives) et à la conjoncture économique défavorable au secteur agricole, tant pour les «terres noires » russes qu'ukrainiennes, et en dépit de politiques, à maints égards différentes, menées par les deux pays. En effet, la Russie se lance vite dans une politique de privatisation sauvage dès le début des années 1990, tandis que l'Ukraine commence par des réformes politiques avant d'entreprendre une certaine libéralisation du marché foncier à partir du milieu des années 1990. Cette évolution parallèle vide de sens toute explication classique du succès ou de la faillite des réformes économiques et foncières, en particulier à partir d'une pure logique économique ou de distribution de droits de propriété, ou de la force (ou faiblesse de l'État), ou encore de l'idéologie (héritage du communisme). L'auteur montre parfaitement que l'appropriation des réformes (et des terres) par certaines élites locales ne relève ni de leur idéologie ni de l'effondrement des autorités centrales, mais, tout au contraire, de leur ancrage au territoire et de leur capacité à profiter de la conjoncture tant économique que politique en faisant levier sur leurs réseaux locaux. Cet ouvrage présente de manière originale la mise en place réelle et quotidienne de ces mesures, la manière dont les acteurs impliqués les conçoivent et se les approprient. On sort ainsi de tout mécanisme téléologique (la «transition») pour rendre parfaitement compte des interactions complexes qui ont été à l'origine de ce résultat. Pour mieux asseoir ses arguments, l'auteur dépasse les limites des sources officielles pour recourir à des interviews et à des récits, notamment concernant certains contrats « fictifs » (recours à des prête-noms).

5 Le premier chapitre étudie l'économie de la pénurie pendant la phase dite de "transition": les difficultés soviétiques en matière d'approvisionnement et de distribution s'aggravent $\mathrm{du}$ fait de l'effondrement des réseaux officiels; le secteur agricole se trouve ainsi sans outils ni matières premières, avec des difficultés majeures pour acheminer ses produits vers la ville; l'endettement des unités de production s'accroît et réduit fortement la rentabilité de toute opération de privatisation. C'est dans ce contexte que les directeurs de kolkhozes luttent pour conserver leur main-d'œuvre (principale ressource dont ils disposent) et leurs terres, l'argument étant qu'une privatisation partielle serait impossible à mener à bien, à cause des liens étroits, en termes d'assolement, passages, techniques, etc., entre les différentes parcelles. Avec l'aide des élites politiques locales, les directeurs des fermes collectives garantissent à ceux qui restent au kolkhoze crédits, ressources et débouchés pour leurs produits, tout en mobilisant ces mêmes réseaux pour entraver l'activité des premières fermes individuelles.

Quelles sont les raisons qui conduisent ces élites locales à agir ainsi ? Le chapitre II avance une réponse : ces élites ne sont pas hostiles au marché ; bien au contraire, leurs comportements répondent parfaitement aux pressions venant de ces mêmes marchés dans la conjoncture particulière des années 1990. Dans un premier temps, les responsables politiques locaux et les directeurs de kolkhoze parviennent à leurs buts en vidant de toute signification le transfert des droits de propriété aux kolkhoziens, en principe libres de quitter le kolkhoze. En particulier, l'absence d'un vrai cadastre rend impossible l'identification de la ou des parcelles concernées par les titres de propriété attribués à chaque famille de kolkhozien.

7 Ensuite, en admettant qu'une parcelle ait été repérée et officiellement attribuée, les réseaux de crédit demeurent inaccessibles aux kolkhoziens. Car en l'absence d'un 
véritable système de crédit rural, les garanties fournies par les élites locales, voire par le kolkhoze lui-même, demeurent le principal moyen d'accès aux ressources.

8 Pourtant, malgré ces difficultés, un certain nombre de fermes individuelles surgissent. Le chapitre III en étudie les chiffres ainsi que l'origine sociale des fondateurs. Deux grandes catégories de fermiers privés apparaissent ainsi : élites locales et marginaux (femmes seules, personnes d'autres régions ou ethnies, sans beaucoup de ressources).

9 L'hostilité envers ces exploitations et la conjoncture économique défavorable encouragent même, à partir de la seconde moitié des années 1990, un regain d'intérêt pour les kolkhozes, (ch. IV). À l'aide d'interviews, l'auteur évoque les sentiments de frustration des " entrepreneurs » et le sentiment d'impuissance des kolkhoziens face à des élites locales qui n'hésitent pas à avoir recours à toute forme de pression afin de parvenir à leurs fins.

10 Il en résulte (ch. $\mathrm{V}$ ) une intensification du travail dans les kolkhozes, du fait de la pénurie de machines et du manque de crédits ; la plupart des kolkhoziens, bien qu'officiellement libres de quitter l'exploitation et de vendre leur part, préfèrent rester, faute d'alternatives. Tout comme à l'époque soviétique, voire même davantage, ils préfèrent être payés en nature, du fait de l'inflation galopante, ce qui accroît leur dépendance à la fois à l'égard du kolkhoze et des élites locales.

11 En résumé, cet ouvrage est important, car il va au-delà d'une représentation purement formelle et théorique de la " privatisation " pour l'étudier " en situation », dans le cadre d'une analyse détaillée et rigoureuse à la fois. Un reproche pourrait être adressé à l'auteur : trop d'intuitions et de pistes de recherches avancées tout au long de l'ouvrage ne sont pas développées. En même temps, c'est là une confirmation de la valeur d'un chercheur dont nous attendons avec impatience les prochains travaux. 